\title{
NOTCH2 in breast cancer: association of SNP rs11249433 with gene expression in ER-positive breast tumors without TP53 mutations
}

\author{
Yi-Ping Fu+1, Hege Edvardsen+2,3, Alpana Kaushiva1, Juan P Arhancet ${ }^{1}$, Tiffany M Howe ${ }^{4}$, Indu Kohaar1, Patricia Porter- \\ Gill1, Anushi Shah', Hege Landmark-Høyvik2, Sophie D Fosså3,5, Stefan Ambs, Bjørn Naume6, Anne-Lise Børresen- \\ Dale2,3, Vessela N Kristensen2,3,7 and Ludmila Prokunina-Olsson*1
}

\begin{abstract}
Background: A recent genome-wide association study (GWAS) has identified a single nucleotide polymorphism (SNP) rs 11249433 in the 1 p11.2 region as a novel genetic risk factor for breast cancer, and this association was stronger in patients with estrogen receptor (ER)+ versus ER- cancer.

Results: We found association between SNP rs 11249433 and expression of the NOTCH2 gene located in the 1p11.2 region. Examined in 180 breast tumors, the expression of NOTCH2 was found to be lowest in tumors with TP53 mutations and highest in TP53 wild-type/ER+ tumors $(p=0.0059)$. In the latter group, the NOTCH2 expression was particularly increased in carriers of the risk genotypes (AG/GG) of rs 11249433 when compared to the non-risk AA genotype ( $p=0.0062$ ). Similar association between NOTCH2 expression and rs 1249433 was observed in 60 samples of purified monocytes from healthy controls $(p=0.015)$, but not in total blood samples from 302 breast cancer patients and 76 normal breast tissue samples. We also identified the first possible dominant-negative form of NOTCH2, a truncated version of NOTCH2 consisting of only the extracellular domain.

Conclusion: This is the first study to show that the expression of NOTCH2 differs in subgroups of breast tumors and by genotypes of the breast cancer-associated SNP rs11249433. The NOTCH pathway has key functions in stem cell differentiation of ER+ luminal cells in the breast. Therefore, increased expression of NOTCH2 in carriers of rs 11249433 may promote development of $\mathrm{ER}^{+}$luminal tumors. Further studies are needed to investigate possible mechanisms of regulation of NOTCH2 expression by rs 1249433 and the role of NOTCH2 splicing forms in breast cancer development.
\end{abstract}

\section{Background}

Several genome-wide association studies (GWAS) in individuals of European ancestry have identified novel genomic regions associated with risk of breast cancer (BC) [1-7]. One of the associated variants was a single nucleotide polymorphism (SNP) rs11249433 located within the pericentromeric region on chromosome $1 \mathrm{p} 11.2$ [4]. The association was found to be stronger with estrogen receptor (ER)+ than with ER- cancer [4]. Decreased genetic recombination rates within pericen-

* Correspondence: prokuninal@mail.nih.gov

1 Laboratory of Translational Genomics, Division of Cancer Epidemiology and Genetics, National Cancer Institute, National Institutes of Health, Bethesda, MD, USA

+ Contributed equally

Full list of author information is available at the end of the article tromeric regions can contribute to large linkage disequilibrium (LD) blocks [8]. As a result, rs11249433 might be in LD with many other variations located over a large distance. The region surrounding rs 11249433 is poorly covered in the International HapMap project [9] due to a high degree of segmental duplications that map to both sides of centromere on chromosome 1. However, rs11249433 itself is located in a region uniquely mapped to 1 p11.2. Given the complicated genomic landscape, we did not perform fine-mapping or resequencing studies of this region, but sought to identify a possible molecular phenotype functionally important for breast carcinogenesis and related to this genetic association.

The heterogeneity of $\mathrm{BC}$ includes diverse molecular characteristics, and variations in clinical outcomes and 
treatment responses. BC patients can be categorized into different groups based on cellular morphology and expression of estrogen receptor (ER), progesterone receptor (PR), and human epidermal growth factor receptor 2 (HER-2) [10]. Mutational status of TP53, a tumor suppressor gene, is also of strong prognostic significance for $\mathrm{BC}$ [11]. Previous findings from mRNA expression profiling have identified several molecular categories of $B C$, such as luminal-A, luminal-B, normal breast-like, HER-2 positive and basal-like types [12-14]. These categories represent clinically distinct patient groups [13,14], and correspond to different breast tumor subtypes with respect to ER and TP53 mutation status: ER+ tumors are generally identified as luminal-like subtype [14], while tumors with TP53 mutations usually belong to the basallike type [15].

In this study, we observed a distinct expression profile of the NOTCH2 gene in various tumor subtypes. Furthermore, the association between rs11249433 and increased expression of $\mathrm{NOTCH} 2$ was found in patients with $\mathrm{ER}^{+}$ breast tumors without TP53 mutations. We also identified a unique splicing form of NOTCH2 consisting of only the extracellular domain and thus predicted to have a dominant-negative function compared to the full-length form of the gene.

\section{Results and Discussion}

NOTCH2 as a candidate gene for $\mathrm{BC}$ risk in the $1 \mathrm{p} 11.2$ region

Several studies have shown that cancer-associated SNPs identified by GWAS are regulatory variants that can be linked to altered gene expression [16-19]. Working under the hypothesis that the $\mathrm{BC}$-associated rs11249433 may regulate mRNA expression of genes in the surrounding region, we analyzed microarray data for the expression of five genes located within a $1 \mathrm{Mb}$ region telomeric from rs11249433 (ADAM30, NOTCH2, NOTCH2NL, $F A M 72 B$, and SRGAP2). There were no genes between this SNP and the centromere (Figure 1). Two other genes from this region, LOC647121, a non-coding pseudogene, and FCGR1B, which belongs to a family of highly similar genes, were not present on the array and thus were not examined here. Based on expression analysis in 108 breast tumor samples, there was a suggestive association between rs11249433 risk genotypes (AG and GG) and increased expression of the Notch homolog 2 gene (NOTCH2, p $=0.054)$ and decreased expression of the Notch homolog $2 \mathrm{~N}$-terminal-like gene (NOTCH2NL, $\mathrm{p}=$ 0.038) (Table 1). The four known NOTCH proteins (NOTCH1 - 4) are highly conserved transmembrane receptors found in all multicellular organisms [20]. Interactions between membrane-bound ligands Jagged1, Jagged2, Delta1 and the extracellular domains of $\mathrm{NOTCH}$ proteins trigger a cascade of proteolytic cleavages that result in a release of the notch intracellular domain (NICD) and induced expression of target genes involved in response to hypoxia, stem cell maturation, migration and inhibition of differentiation [20-22]. The NOTCH signaling pathway has been well-studied as one of the underlying mechanisms and potential therapeutic targets for BC [23,24]. However, the majority of information about the NOTCH pathway is related to NOTCH1 gene, while the potential role of $\mathrm{NOTCH} 2$ gene is still not well established. Interestingly, a recent report indicated that a higher expression level of $\mathrm{NOTCH} 2$ can be found in lowgrade/well-differentiated breast tumors as compared to poorly-differentiated tumors [25].

Exons $2-4$ of NOTCH2 are included in NOTCH2NL gene, and this region is duplicated at 1q21.1, on the other side of centromere, while exons 5 - 34 of NOTCH2 are uniquely mapped to the $1 \mathrm{p} 11.2$ region. The full-length NOTCH2 has 34 exons that encode a protein of 2471 amino acids with an extracellular domain containing multiple epidermal growth factor (EGF)-like repeats, and NOTCH2NL has 4 exons and encodes a protein of 235 amino acids with only one EGF-like repeat. The role of NOTCH2NL is not clear and, given its mapping to multiple locations and the lack of protein domains, expression of NOTCH2NL was not studied further.

\section{NOTCH2 expression analysis}

To corroborate our observations of the suggestive association between rs11249433 and NOTCH2 expression, we employed the sensitive and quantitative reverse-transcriptase PCR (RT-PCR) method in an extended set of 180 breast tumors, 104 of which were used for the initial microarray analysis. We used a custom-designed expression assay for terminal exons 33 and 34 of NOTCH2 to detect the full-length transcripts (FL-NOTCH2). Expression of $F L-N O T C H 2$ was increased in tumors from individuals with risk genotypes AG and GG of rs11249433 compared to non-risk AA genotypes by 1.24 and 1.12 fold, respectively ( $p=0.066$, Additional File 1 , Table S1). The expression was found to be significantly increased in tumors from patients with higher age at diagnosis $(\mathrm{p}=$ 0.0007 ) and decreased in tumors with TP53 mutations ( $\mathrm{p}$ $=0.0056$, Additional File 1, Table S1). However, no association was observed between NOTCH2 expression and tumor grade or stage (data not shown).

The tumor suppressor gene TP53 regulates multiple vital cell functions. Germline TP53 mutations found in patients with Li-Fraumeni syndrome [26] are associated with early development of tumors, while the restoration of the gene function causes regression of tumors by apoptosis and senescence [27]. Somatic mutations in the TP53 gene are found in $20-30 \%$ of all breast tumors [28,29], but the frequency varies by tumor stage and subtype. For example, more than $80 \%$ of basal-like tumors, while only 


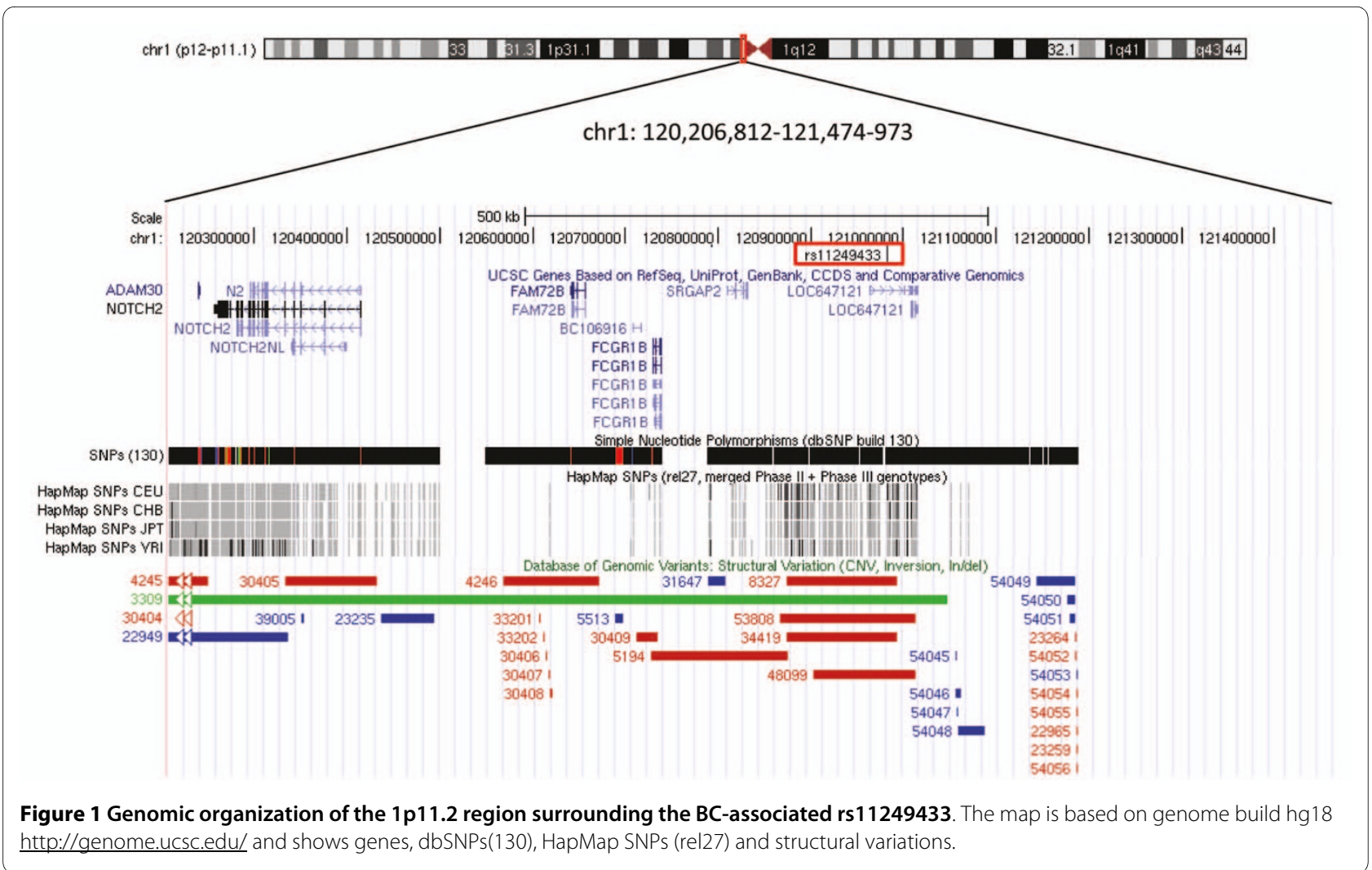

13\% of ER+ luminal tumors carry TP53 mutations [15]. Since different subtypes of BC have been associated with distinct gene expression profiles [12-14], we examined the NOTCH2 expression in subgroups of breast tumors according to their ER and TP53 status. There was a strong difference in $\mathrm{NOTCH} 2$ expression in these subgroups $(\mathrm{p}=0.0059$, Figure $2 \mathrm{~A}$ and Additional File 1 , Table S1), the expression was lower in tumors with TP53 mutations. In tumors with wild-type (wt) TP53 gene, NOTCH2 expression was higher in $\mathrm{ER}^{+}$compared to ERtumors. Among patients with TP53wt/ER+ tumors, NOTCH2 expression was increased by 1.52 and 1.11 fold in individuals with the risk AG and GG genotypes, respectively, compared to those with the non-risk AA genotype of rs11249433 ( $\mathrm{p}=0.0062$, Figure $2 \mathrm{~B}$ and Additional File 1, Table S1). SNP rs11249433 is located $\sim 600$ $\mathrm{kb}$ away from NOTCH2. The non-linear increase of $\mathrm{NOTCH} 2$ expression with allele counts may indicate that rs11249433 is not the actual risk factor but is in LD with the best candidate that can be located at any distance.

There was no association of rs 11249433 with NOTCH2 expression in RNA from peripheral blood of 302 women with a previous breast cancer diagnosis (Additional File 1, Table S2), or in 76 samples of adjacent normal breast tissue (Additional File 1, Table S3). According to GNF Expression Atlas 2 data http://biogps.gnf.org/ \#goto=genereport\&id=4853 and results by Ohishi et al. [30], the highest $\mathrm{NOTCH} 2$ expression of all blood fractions is found in monocytes while it is low in all other blood cells. Using purified peripheral blood monocytes from 60 healthy controls, we observed that individuals carrying risk genotypes of rs11249433 had significant increase of NOTCH2 expression ( $\mathrm{p}=0.015$, Additional File 1, Table S4), similar to the pattern in breast tumors.

The pericentromeric NOTCH2 region is reported to contain large structural variations (amplifications and deletions) detectable by high-resolution comparative genomic hybridization (CGH) analysis [31]. We hypothesized that these copy number variations $(\mathrm{CNVs})$ might affect mRNA expression of $\mathrm{NOTCH} 2$, and measured CNVs by two quantitative PCR assays located in intron 1 and upstream from $\mathrm{NOTCH} 2$. We used DNA from breast tumors $(\mathrm{n}=97)$ and blood samples from $\mathrm{BC}$ patients $(\mathrm{n}=$ 295) in which expression analysis was performed. $\mathrm{NOTCH} 2$ expression was not significantly correlated with CNVs in both samples (Additional File 1, Table S5). Inclusion of $\mathrm{CNVs}$ into the multivariable model did not affect the association between rs11249433 and NOTCH2 expression (Additional File 1, Table S6). Another SNP, rs10923931, located within intron 2 of $N O T C H 2$ has been reported to be associated with risk of type 2 diabetes [32]. We did not observe any effect of rs10923931 on NOTCH2 
Table 1: Results of microarray analysis for 5 genes within $1 \mathrm{Mb}$ from rs11249433 in the $1 \mathrm{p} 11.2$ region.

\begin{tabular}{|c|c|c|c|c|c|c|}
\hline Gene/SNP & Position, bp ${ }^{+}$ & rs11249433 & $\mathbf{N}$ & Fold* & $95 \% \mathrm{Cl}$ & p-value* \\
\hline \multirow[t]{3}{*}{ ADAM30 } & $\begin{array}{c}\text { chr1: } 120,237,679- \\
120,240,636\end{array}$ & $A A$ & 35 & 1.00 & $0.90-1.11$ & 0.378 \\
\hline & & AG & 41 & 1.06 & $0.96-1.16$ & \\
\hline & & GG & 13 & 0.93 & $0.80-1.09$ & \\
\hline \multirow[t]{3}{*}{$\mathrm{NOTCH} 2$} & $\begin{array}{c}\text { chr1: } 120,279,260- \\
120,413,799\end{array}$ & $A A$ & 41 & 1.00 & $0.85-1.18$ & 0.054 \\
\hline & & AG & 45 & 1.28 & $1.10-1.50$ & \\
\hline & & GG & 17 & 1.16 & $0.91-1.46$ & \\
\hline \multirow[t]{3}{*}{ NOTCH2NL } & $\begin{array}{c}\text { chr1: } 120,338,694-120,398- \\
362\end{array}$ & $A A$ & 41 & 1.00 & $0.75-1.33$ & 0.038 \\
\hline & $\begin{array}{c}\text { chr1: } 143,920,468- \\
144,009,723\end{array}$ & AG & 47 & 0.64 & $0.49-0.83$ & \\
\hline & & GG & 19 & 0.70 & $0.47-1.04$ & \\
\hline \multirow[t]{3}{*}{ FAM72B } & $\begin{array}{c}\text { chr1: } 120,640,935- \\
120,657,204\end{array}$ & $A A$ & 41 & 1.00 & $0.68-1.47$ & 0.218 \\
\hline & & AG & 47 & 0.76 & $0.53-1.10$ & \\
\hline & & GG & 19 & 0.59 & $0.35-1.00$ & \\
\hline \multirow[t]{3}{*}{ SRGAP2 } & $\begin{array}{c}\text { chr1: } 120,808,675- \\
120,832,674\end{array}$ & AA & 41 & 1.00 & $0.82-1.21$ & 0.652 \\
\hline & $\begin{array}{c}\text { chr1: } 204,582,823- \\
204,648,014\end{array}$ & AG & 48 & 1.03 & $0.86-1.24$ & \\
\hline & & GG & 19 & 0.89 & $0.68-1.17$ & \\
\hline rs11249433 & chr1: $120,982,136$ & & & & & \\
\hline
\end{tabular}

+ Based on the UCSC genome browser on Human Mar. 2006 assembly (hg18).

*Generalized linear model adjusted for age, ER and PR status.

expression in breast tumor tissue (Additional File 1, Table $\mathrm{S} 1$ ) or in blood of BC patients (Additional File 1, Table S2).

\section{Assessment of possible NOTCH2 function through expression and pathway analyses in $\mathrm{NCl}-60$ cell lines}

NOTCH 2 belongs to a family of transmembrane receptors involved in regulation of cell-cell communication, cell proliferation, differentiation, and apoptosis [33]. However, the specific role of NOTCH2 is not yet well established. To assess the potential function of $\mathrm{NOTCH} 2$, we used expression data generated in 60 human cell lines representing several cancer types (NCI-60 cell line expression set [34]). We examined correlation patterns between NOTCH2 and all the genes represented on Affymetrix HG-U133 arrays, as previously described
[35]. After adjustment for multiple comparisons, 469 and 758 genes showed significantly positive and negative correlations with $\mathrm{NOTCH} 2$, respectively. These genes were analyzed for enrichment of Gene Ontology (GO) categories. The analysis identified statistically significant enrichment of the integrin signaling pathway $(\mathrm{p}=1.87 \times$ $\left.10^{-7}\right)$ and cell structure and motility $\left(\mathrm{p}=6.96 \times 10^{-9}\right)$ for genes with positive correlations with $\mathrm{NOTCH} 2$, and enrichment for nucleic acid binding $\left(\mathrm{p}=1.88 \times 10^{-17}\right)$ and nucleoside, nucleotide and nucleic acid metabolism ( $\mathrm{p}=$ $\left.1.20 \times 10^{-10}\right)$ for genes with negative correlations with NOTCH2 (Table 2). These results supported the potential role of $\mathrm{NOTCH} 2$ in maintaining cell shape, structure and motility [36], and NOTCH-mediated regulation of integrin affinity [37]. 

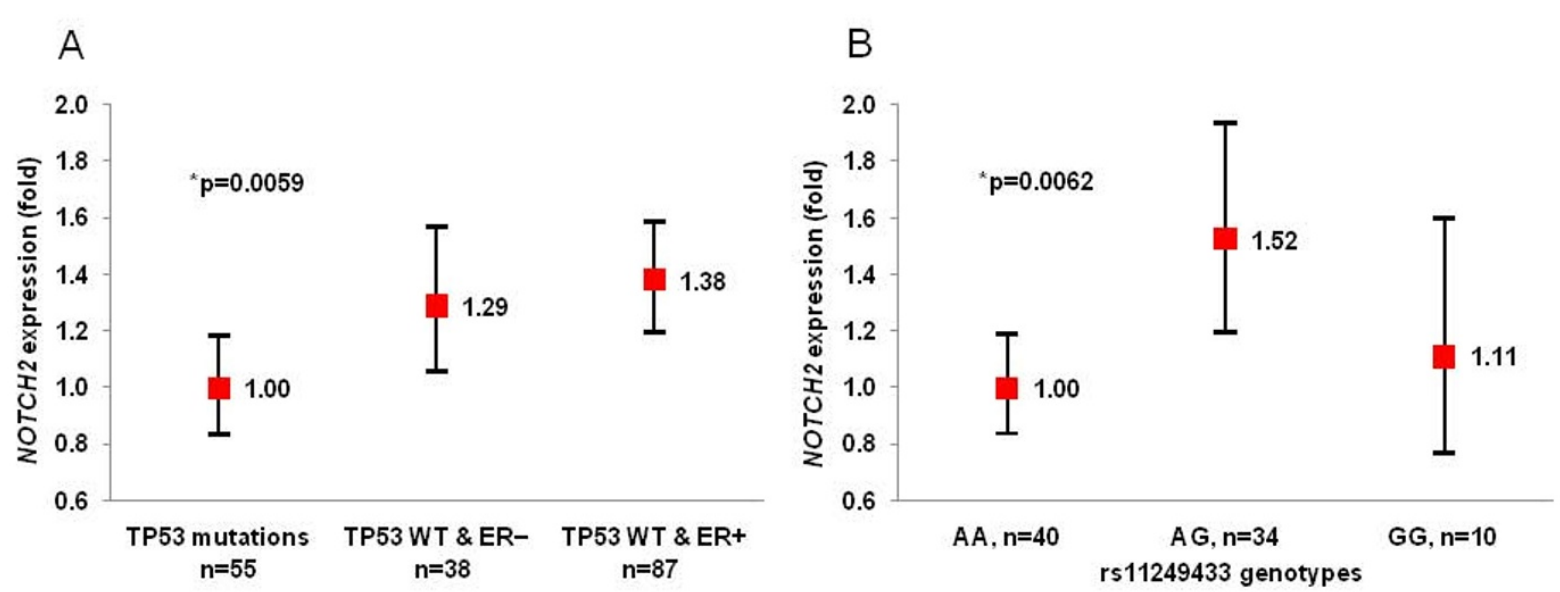

Figure 2 NOTCH2 expression in breast tumors. A. Stratified by ER and TP53 mutational status; B. Stratified by genotypes of rs 11249433 in TP53wt/ $E R^{+}$tumors. Expression is shown as fold difference with 95\% confidence intervals compared to reference groups; $\mathrm{p}$-values are for generalized linear model adjusted for plate effect, age at diagnosis, race, ER/PR and TP53 mutational status when applicable.

\section{Expression and functional characterization of splice variants of $\mathrm{NOTCH} 2$}

We tested for potential alternative splicing events within the NOTCH2 gene by performing a 5 rapid amplification of cDNA ends (RACE). One of the transcripts with alternative 5'end was identical to NOTCH2NL (data not shown). Another alternative splicing form was transcribed from an alternative exon 1a and was terminated by an alternative stop codon after exon 16 of the NOTCH2 gene (GenBank GQ231534). This splicing form encodes a truncated (TR) protein of 863 amino acids identical to a fragment of the full-length (FL) NOTCH2 protein (amino acids 40 - 827). The TR-NOTCH2 protein is predicted to have a dominant negative function relative to FL-NOTCH2, as it has an extracellular but no intracellular domain (Figure 3A). FL-NOTCH2 protein has 19 epidermal growth factor (EGF)-like repeats, while the TR-NOTCH2 has only 8 repeats, thus the functional properties of extracellular domains of these two protein forms and their interactions with ligands might be different.

We cloned both splicing forms of $\mathrm{NOTCH} 2$ and examined their protein expression in human cell lines HeLa and 293T. NOTCH proteins undergo several stages of proteolytic cleavages: non-activating cleavage at S1 site with furin-like convertase occurs during protein processing and generates two protein subunits - extracellular and transmembrane/intracellular; S2 activating cleavage occurs in response to ligand binding; S3 activating cleavage by $\gamma$-secretase generates the notch intracellular domain (NICD) that migrates to the nucleus and activates downstream targets [22]. The use of $\gamma$-secretase inhibitors that prevent $\mathrm{NOTCH}$ cleavage at S3 site has been targeted as a promising tool for anti-cancer therapy [38]. The expected sizes for FL-NOTCH2-Halo and TR$\mathrm{NOTCH} 2-$ Halo expression constructs with C-terminal Halo-tags are $\sim 298 \mathrm{kDa}$ and $\sim 125 \mathrm{kDa}$, respectively. The results of the Western blot (Figure $3 \mathrm{~B}$ ) suggested that the observed size of $\sim 200 \mathrm{kDa}$ (with Halo-Tag of $33 \mathrm{kDa}$ ) for FL-NOTCH2-Halo is likely to correspond to C-terminal intracellular part of protein after non-activating $\mathrm{S} 1$ cleavage. The shorter bands might correspond to forms after activation cleavage events at S2 and S3 sites. For TRNOTCH2-Halo that lacks the cleavage site, low protein expression was detected by a band of a size corresponding to the unprocessed protein $(\sim 125 \mathrm{kDa})$. Confocal imaging of both expression constructs showed a differential pattern of cellular localization for these forms. The expression pattern for FL-NOTCH2-Halo suggested that the $\mathrm{C}$-terminal intracellular protein part is localized in the cytoplasm and in the peri-nuclear space (Figure 3C). In contrast, the TR-NOTCH2 form, which lacks the cleavage sites, is found in a granule-type pattern, possibly anchored to cell membrane (Figure 3D).

mRNA expression of TR-NOTCH2 was lower than that of $F L-N O T C H 2$ by 10.7 fold in blood samples, by 25.4 fold in tumor breast tissue and by 33.1 fold in normal breast tissue (Additional File 1, Figure S1). There was also a great variation in relative expression of $\mathrm{FL}-\mathrm{NOTCH} 2$ and TR-NOTCH2 in a panel of human tissues and NCI60 cancer cell lines, but the significance of this differential expression is unknown (Additional File 1, Table S7). The pattern of NOTCH2 mRNA expression in different tumor types and genotype groups was similar for both forms (Additional File 1, Table S1, Table S2, and Table S8), but due to a much lower level of expression of the TR- 
Table 2: Summary of PANTHER pathway enrichment analysis for transcripts correlated with NOTCH2 in the NCI-60 set of cell lines

\begin{tabular}{|c|c|c|c|c|c|c|}
\hline \multicolumn{2}{|c|}{ PANTHER categorya } & \multirow{2}{*}{$\begin{array}{l}\text { No. of genes in } \\
\text { reference list }\end{array}$} & \multirow{2}{*}{$\begin{array}{l}\text { Observed no. of } \\
\text { genes in category }\end{array}$} & \multirow{2}{*}{$\begin{array}{l}\text { Expected no. of } \\
\text { genes in category }\end{array}$} & \multirow{2}{*}{$\begin{array}{l}\text { Over(+)/under(-) } \\
\text { representation }\end{array}$} & \multirow[t]{2}{*}{ p-value ${ }^{b}$} \\
\hline \multicolumn{2}{|c|}{ For genes with positive correlation with NOTCH2 expression } & & & & & \\
\hline BP00285 & Cell structure and motility & 990 & 65 & 27.7 & + & $6.96 \times 10^{-9}$ \\
\hline P00034 & Integrin signalling pathway & 217 & 26 & 6.1 & + & $1.87 \times 10^{-7}$ \\
\hline MF00091 & Cytoskeletal protein & 698 & 47 & 19.5 & + & $1.22 \times 10^{-6}$ \\
\hline BP00125 & Intracellular protein traffic & 892 & 51 & 25.0 & + & $4.59 \times 10^{-5}$ \\
\hline MF00261 & $\begin{array}{l}\text { Actin binding cytoskeletal } \\
\text { protein }\end{array}$ & 342 & 29 & 9.6 & + & $3.46 \times 10^{-5}$ \\
\hline \multicolumn{7}{|c|}{ For genes with negative correlation with NOTCH2 expression } \\
\hline MF00042 & Nucleic acid binding & 2214 & 187 & 100.1 & + & $1.88 \times 10^{-17}$ \\
\hline ВР00031 & $\begin{array}{l}\text { Nucleoside, nucleotide and } \\
\text { nucleic acid metabolism }\end{array}$ & 2837 & 203 & 128.3 & + & $1.20 \times 10^{-10}$ \\
\hline BP00047 & Pre-mRNA processing & 264 & 35 & 11.9 & + & $4.74 \times 10^{-6}$ \\
\hline BP00048 & mRNA splicing & 196 & 29 & 8.9 & + & $1.04 \times 10^{-5}$ \\
\hline
\end{tabular}

aPANTHER accession number for pathway (P), biological process (BP), or molecular function (MF) http://www.pantherdb.org/.

${ }^{b} p$-values of binomial test with Bonferroni correction for multiple testing.

NOTCH2 form and a higher variability of this expression, the results were mostly not statistically significant (Additional File 1, Table S8). Therefore, the association between rs11249433 and expression of NOTCH2 in human breast tumors is likely to be general and unspecific for particular splicing forms. However, as a result of a much higher expression level of $F L-N O T C H 2$ compared to TR-NOTCH2 in breast tissue, the effect of $F L$ NOTCH2 might be predominant.

\section{Conclusions}

Large-scale GWAS for BC identified multiple genomic regions that harbor genetic risk factors for the disease. In this study, we aimed to identify a molecular phenotype related to the recently reported genetic association within the $1 \mathrm{p} 11.2$ region [4]. We found that the $\mathrm{BC}$-associated rs11249433 located within this region, is associated with mRNA expression of NOTCH2 gene. Most unexpectedly, the association between rs11249433 and NOTCH2 expression was dependent on the mutational status of the tumor suppressor gene TP53 and ER status of the tumors. Among other scenarios this suggests that either the estrogen receptor or the TP53 may have a function in the regulation of $\mathrm{NOTCH} 2$ expression, as the restoration of $\mathrm{p} 53$ expression has been shown to affect NOTCH1 expression $[39,40]$. An active NOTCH pathway is important for the induction of breast stem cells to differentiate into luminal cells of breast ducts [41]. Thus, increased or persistent activation of $\mathrm{NOTCH} 2$ expression may favor development of $\mathrm{ER}^{+}$breast carcinomas in TP53wt tumors. Indeed, the original GWAS association with rs11249433 was stronger in $\mathrm{ER}^{+}$compared to ER- cancer [4]. Future research will have to examine how rs11249433 influences NOTCH2 expression and what function TP53 and the estrogen receptor may have in regulation of $\mathrm{NOTCH} 2$ expression. We also identified the first possible dominant-negative truncated form of NOTCH2. The exact role of this form in different tissues and biological conditions warrants further studies.

\section{Materials and methods}

Human breast tissue and blood samples

Fresh-frozen tumor specimens and blood samples were obtained from breast cancer patients. The US breast tissue samples (100 tumor samples and 90 adjacent normal breast tissue) were previously described [42]. Briefly, patients were recruited at the University of Maryland Medical Center (UMD), the Baltimore Veterans Affairs Medical Center, Union Memorial Hospital, Mercy Medical Center, and the Sinai Hospital in Baltimore between 1993 and 2003. All patients signed a consent form and completed an interviewer-administered questionnaire. Clinical and pathological information was obtained from medical records and pathology reports. Disease staging 


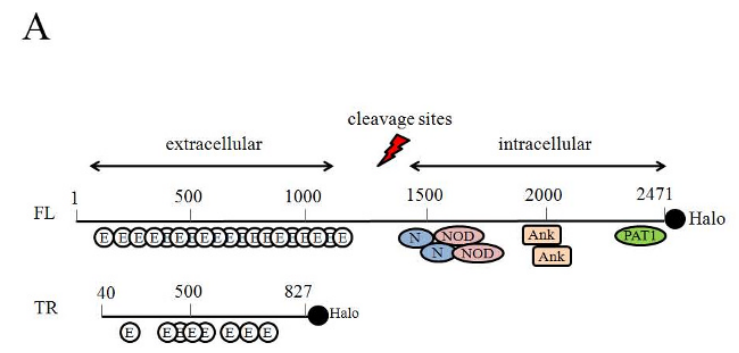

B

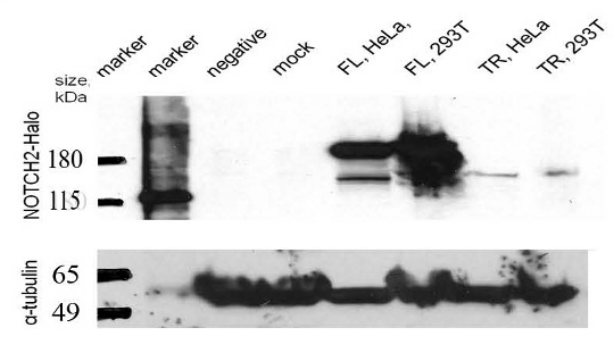

C
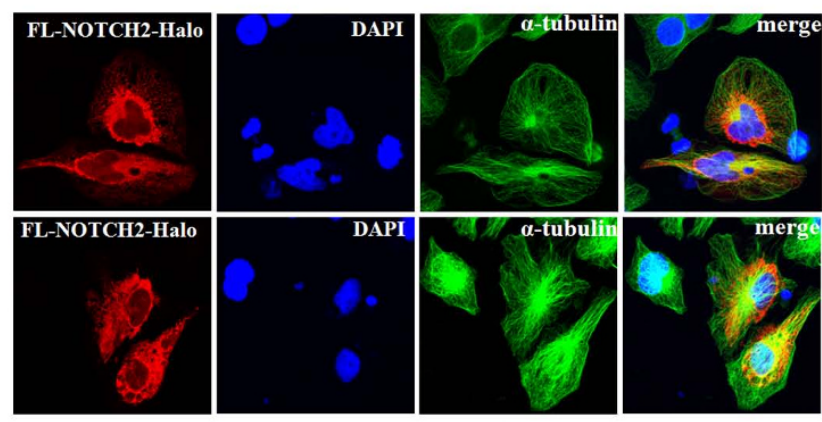

$\mathrm{D}$

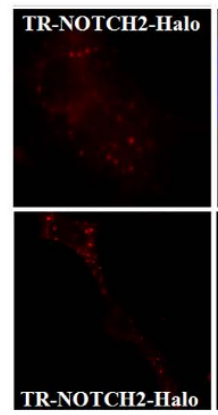

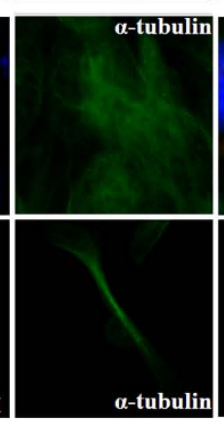

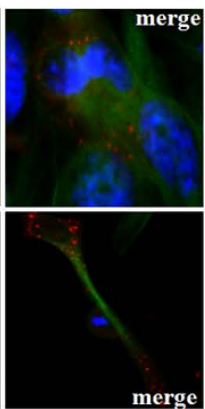

Figure 3 Splicing variation of NOTCH2. A. Schematic representation of recombinant constructs for full-length (FL) and truncated (TR) NOTCH2 protein isoforms fused with C-terminal Halo-tag protein (marked as Halo). Intracellular part of FL-NOTCH2 consists of two LNRs (Lin-12/Notch repeat domains, marked as N), two NOTCH protein domains (marked as NOD), two ankyrin repeats (marked as ANK) and a topoisomerase Il-associated protein domain (marked as PAT1). B. Western blot showing expression of recombinant FL-NOTCH2-Halo and TR-NOTCH2-Halo constructs in HeLa and 293T cell lines. The lanes show two different size markers, negative control (no DNA), mock control (vector only) and results of transfections with FLNOTCH2-Halo and TR-NOTCH2-Halo in HeLa and 293T cells. C. Confocal imaging of protein expression for the recombinant construct FL-NOTCH2Halo (red) in HeLa cells. Untransfected cells in the same field serve as negative controls. Antibodies against a-tubulin were used to stain the cytoskeleton (green) while DAPI was used to stain the cell nuclei (blue). D. Confocal imaging of protein expression for the recombinant construct TR-NOTCH2Halo (red) in HeLa cells. Untransfected cells in the same field serve as negative controls. Antibodies against a-tubulin were used to stain the cytoskeleton (green) while DAPI was used to stain the cell nuclei (blue).

was performed according to the tumor-node-metastasis (TNM) system of the American Joint Committee on Cancer/the Union Internationale Contre le Cancer (AJCC/ UICC). The Nottingham system was used to determine the tumor grade. The collection of tumor specimens, survey data, and clinical and pathological information was reviewed and approved by the University of Maryland Institutional Review Board for the participating institutions (UMD protocol \#0298229). IRB approval of this protocol was then obtained at all institutions (Veterans Affairs Medical Center, Union Memorial Hospital, Mercy Medical Center, and Sinai Hospital). The project was also reviewed and approved by the NIH Office of Human Subjects Research (OHSR \#2248).

Breast tumor samples from Norway $(\mathrm{n}=116)$ were collected in 1995-1998 from 5 hospitals located in the Oslo region [43]. Histological tumor type, tumor size, and nodal involvement were analyzed, and the disease was staged according to the TNM system. Tumor grading was performed according to Elston and Ellis [44] and tumor slides were screened for vascular invasion. Blood samples $(\mathrm{n}=316)$ were collected from breast cancer survivors treated with radiotherapy at the Norwegian Radium Hospital between 1998 and 2002 and invited in 2004 to participate in a study assessing late clinical and biochemical effects $[45,46]$. The project was reviewed and approved by the NIH Office of Human Subjects Research (OHSR \#4700). Monocytes from fresh blood obtained from anonymous blood donors at the NIH Blood Bank, were described previously [47].

Overall, all blood samples were collected from patients of European ancestry, while for breast tissue 75\% samples were from patients of European ancestry and 25\% of African ancestry. Race of patients was included as a covariate in the generalized linear model when relevant.

\section{ER, PR status evaluation}

For the US samples, the ER status was determined immunohistochemically using formalin-fixed, paraffin-embedded tissue slides and the ready-to-use monoclonal antibody (clone 6F11, Ventana Medical Systems, Tucson, AZ). The ER status was determined according to the reference range set by the ChromaVision ACIS assisted quantitative image analysis software (Clarient Diagnostic 
Services, Irvine, CA) and was scored as negative/positive. The PR status was abstracted from medical records, as available. For the Norwegian samples, immunostaining was performed using mouse mAb against estrogen receptor (ER) and progesterone receptor (PgR; clones 6F11 and 1A6, respectively; Novocastra, Newcastle on Tyne, United Kingdom). Automated immunostaining systems BioGenex were used for both markers. Immunopositivity was recorded for tumors with $>10 \%$ (ER, PgR) of staining.

\section{TP53 mutation analysis}

Tumors were screened for TP53 mutations as previously described $[43,48]$.

\section{RNA preparation}

Total RNA from fresh-frozen breast tissue samples was isolated using TRIZOL reagent according to the manufacturer's instructions (Invitrogen, Carlsbad, CA). Total RNA from blood cells was isolated from PAX tubes at AROS Applied Biotechnology (Aarhus, Denmark) with an automated procedure utilizing the column-based technologies from Qiagen Inc. (Hilden, Germany). The concentration was measured using a NanoDrop spectrophotometer (NanoDrop Technologies, Wilmington, DE). RNA integrity for each sample was confirmed with the Agilent 2100 Bioanalyzer (Agilent Technologies, Palo Alto, CA).

\section{cDNA preparation}

For each sample, 200-300 ng of total RNA was converted to cDNA with Superscript III kit (Invitrogen) for the US samples or with High-Capacity cDNA Reverse Transcription Kit (Applied Biosystems, Foster City, CA) for the Norwegian samples.

\section{Microarray expression of 5 genes with Agilent 44K whole- genome microarrays}

mRNA expression values for ADAM30, NOTCH2, NOTCH2NL, FAM72B, and SRGAP2 were extracted from a whole-genome expression set for breast tumor samples from Norway (unpublished data Edvardsen, et al.) generated with Agilent whole human genome 44K 60-mer oligo arrays, Agilent Technologies). The arrays were scanned using the Agilent scanner G2565A and signals were extracted using Feature Extraction v9.5. Data were $\log 2$ transformed and, after removal of non-uniform spots and exclusion of population outliers, replicated probes were averaged. The data were quintile normalized using the R package "normalize Between Arrays" from the LIMMA library [49] and missing values imputed using LLS imputation [50]. Information on genotypes, age, ER and PR status was available for 108 breast cancer samples with expression values.

\section{Genotyping}

Pre-developed TaqMan allelic discrimination genotyping assays for SNPs rs11249433 (C__31617470_30) and rs10923931 (C__1188816_10) were purchased from Applied Biosystems. Genotyping was performed in 384well optical plates on the ABI PRISM 7900HT Sequence Detection System (Applied Biosystems) with $10 \mathrm{ng}$ of genomic non-tumor DNA, $0.125 \mu \mathrm{L}$ of $40 \times$ TaqMan SNP genotyping assay, $2.5 \mu \mathrm{L}$ of $2 \times$ TaqMan genotyping master mix (Applied Biosystems) in $5 \mu \mathrm{L}$ reaction volume.

\section{Quantitative Reverse-Transcriptase PCR (qRT-PCR)}

Expression of $\mathrm{NOTCH} 2$ was measured with two customdesigned assays, FL-NOTCH2, targeting a junction between the most terminal exons 33 and 34 and TRNOTCH 2 for the truncated form (information about all assays is presented in Additional File 1, Table S6). Three endogenous controls, glyceraldehyde-3-phosphate dehydrogenase $(G A P D H)$, beta-2-microglobulin $(B 2 M)$ and cyclophilin (PPIA), were selected as appropriate controls based on prior expression studies in breast cancer [51]. All assays were validated on a cDNA panel prepared from a normal breast tissue sample at 8 different RNA concentrations: $1000 \mathrm{ng} / \mu \mathrm{L}, 100 \mathrm{ng} / \mu \mathrm{L}, 10 \mathrm{ng} / \mu \mathrm{L}, 1 \mathrm{ng} / \mu \mathrm{L}, 0.1$ $\mathrm{ng} / \mu \mathrm{L}, 0.01 \mathrm{ng} / \mu \mathrm{L}, 0.001 \mathrm{ng} / \mu \mathrm{L}$, and $0 \mathrm{ng} / \mu \mathrm{L}$. Standard curves constructed for each assay were used for calculation of amplification efficiency (E, \%). To determine optimal amount of cDNA to be used for each assay, several samples representing each tissue type were tested at three 5-fold dilutions of cDNA. We used 2.4 ng of total RNA/ reaction for TR-NOTCH2 assay and $0.6 \mathrm{ng}$ of total RNA/ reaction for all other assays. All plates included two negative controls (genomic DNA and water), and three positive controls prepared from total RNA of MCF7 breast cancer cell line and used at three 5-fold dilutions of cDNA. The positive controls were also used as interplate controls to normalize results between plates. All assays were run in quadruplicates on 384-well plates on ABI PRISM 7900HT Sequence Detection System (Applied Biosystems). For endogenous controls, the reactions were performed with cDNA prepared from $0.6 \mathrm{ng}$ of total RNA, $0.25 \mu \mathrm{L}$ of $20 \times$ TaqMan expression assay and 2.5 $\mu \mathrm{L}$ of $2 \times$ TaqMan Gene Expression master mix (Applied Biosystems) in $5 \mu \mathrm{L}$ reaction volume. For $\mathrm{NOTCH}_{2}$ assays, the reactions were performed with cDNA prepared from 0.6 or $2.4 \mathrm{ng}$ of total RNA, custom-designed primers, $2.5 \mu \mathrm{L}$ of $2 \times$ Power SYBR master mix (Applied Biosystems) in $5 \mu \mathrm{L}$ reaction volume.

\section{CNV analysis}

Two assays were used to quantify $\mathrm{CNV}$ around $\mathrm{NOTCH} 2$ region (Additional File 1, Table $\mathrm{S} 9$ for assay information). A CNV assay $\mathrm{BC} 1$ was designed to map upstream 
NOTCH2 and a CNV assay BC2 located within intron 1 of $\mathrm{NOTCH} 2$, was designed next to an assay that was previously used to validate genomic amplification of this region (Supplementary Table 4 of [31], Chr1tp-38C8, chr1: $120,245,520-120,395,759)$. Each of assays was quantified with qPCR using 5 ng of genomic DNA from corresponding samples (blood or tumor) and $2 \times$ Power SYBR master mix (Applied Biosystems). All plates included two negative controls (water), and three positive controls (20 ng, $4 \mathrm{ng}$ and $0.8 \mathrm{ng}$ of a normal DNA sample). The positive controls were also used as interplate controls to normalize results between plates. All assays were run in quadruplicates on 384-well plates on ABI PRISM 7900HT Sequence Detection System (Applied Biosystems). The CNV assays were normalized by a control RNAseP assay (Applied Biosystems) run in quadruplicates in separate reactions.

\section{Pathway analysis}

Expression data of NCI-60 cell lines on Affymetrix HGU133 arrays that included 39,135 probes covering 18,457 unique annotated transcripts was downloaded from CellMiner Build1.0 [34]. The probe (212377_s_at) residing on the junction of exons 33 and 34 of NOTCH2 (similarly to FL-NOTCH2 expression assay) was selected to calculate the pairwise Pearson's correlation coefficient between this probe and all other probes on HG-U133 chip across the entire NCI-60 cancer cell panel. The false discovery rate (FDR) [52] was set at 5\%, defining the threshold for correlation coefficient as $r=+/-0.39$. The lists of genes that showed significantly positive or negative correlations with NOTCH2 expression were used to determine enrichment for any pathway, biological process, or molecular function using the Compare Gene Lists Tool from the PANTHER Classification System [53] relative to the reference gene list that included all 39,135 probes represented on Affymetrix HG-U133 arrays. Genes that showed positive and negative association with NOTCH 2 were examined separately and the Bonferroni correction was applied for multiple testing.

\section{Statistical analyses}

Expression analysis was performed as follows: for each assay, the mean values of quadruplicates were recalculated based on standard curve slopes to correspond to $\mathrm{E}=$ $100 \%$ of amplification efficiency as $\mathrm{E}=-1+10^{(-1 / \text { slope })} \underline{\mathrm{http}}$ / /www.stratagene.com/techtoolbox/calc/

qpcr_slope_eff.aspx. Distribution of expression values for each of the assays was tested for normality and no significant deviations were observed. The values for all assays were normalized to interplate controls on each plate. The expression values for $\mathrm{NOTCH} 2$ assays were normalized by the geometric mean of all endogenous controls (GAPDH, B2 $M$ and PPIA) according to relative quantifi- cation method $(\mathrm{dCt})$ [54]. A generalized linear model adjusted for applicable covariates (plate effect, age at diagnosis, race, ER/PR and TP53 mutation status) was used to test the association between mRNA expression and SNPs. For correlation analysis, Pearson's correlation coefficients and FDR-adjusted p-values were calculated. All the statistical analyses were performed using SAS/ STAT system version 9.2 (SAS Institute Inc., Cary, NC).

\section{NOTCH2 CDNA cloning, transfection, Western blot and confocal imaging}

5'RACE was performed starting with a mix of total RNA from normal and cancer breast tissue. The 5'RACE cDNA was prepared with SMART RACE cDNA Amplification Kit (Clontech, Mountain View, CA). Using the 5'RACE cDNA as a template, PCR fragments were amplified with a primer for exon 4 of NOTCH2 and a universal RACE linker attached to 5 'end of transcripts. After sequencing and analysis of the PCR fragments, a novel alternative transcription start and exon 1a were identified. Using primers for two transcription starts and two translation stops predicted in the UCSC browser, all four combinations of PCR reactions were attempted on a breast tumor and a normal sample (primers are presented in Additional File 1, Table S9). The successful PCR products were cloned into a pFC8A Halo-tag CMV Flexi vector (Promega, Madison, WI) and multiple clones were sequenced. Only two splicing forms were identified - a known form (NM_024408), representing the full-length FL-NOTCH2 and a novel splicing form, TR-NOTCH2 (GenBank GQ231534). Equal amounts of the constructs were transfected into human HeLa and 293T cell using Lipofectamine 2000 reagent according to instructions (Invitrogen). Non-transfected cells (Lipofectamine only) and cells transfected with empty GFP-tagged pIRES vector (Clontech) served as negative controls. Protein lysates from transfected cells were prepared 48 hours post-transfection and analyzed by Western blot. Similar amounts of protein for each sample were resolved on 4-12\% tris-glycine polyacrylamide gel (Invitrogen) together with prestained Rainbow marker (BenchMark Prestained Protein Ladder, Invitrogen) and Santa-Cruz protein marker (sc2035, Cruz Marker Molecular Weight Standards, Santa Cruz, CA), transferred to nitrocellulose membrane (Invitrogen), blocked with 5\% milk and probed with rabbit anti-Halo (Promega) and mouse $\alpha$-tubulin primary antibodies (ab-7291, Abcam, Cambridge, MA), both at 1:1000 dilution, followed by incubation with secondary HRP-labeled antibodies (sc-2305 donkey anti-rabbit and sc-2302 goat anti-mouse, Santa Cruz, at 1:10,000 dilution) and ECL-detection (GE Healthcare, Pittsburgh, PA). For immunofluorescence analysis, the cells were grown on chamber slides and transfected with the expression constructs with Lipofectamine 2000 reagent according to 
instructions (Invitrogen). 48 hours post-transfection, the cells were permeabilized with $4 \%$ of paraformaldehyde, blocked with 4\% BSA in TBS for $1 \mathrm{hr}$, and incubated with primary rabbit Anti-Halotag antibody (Promega), and mouse $\alpha$-tubulin (ab-7291, Abcam), both at 1:1000 dilution. Cells were incubated with secondary antibody (donkey anti-rabbit Alexa Fluor 594 and donkey anti-mouse Alexa Fluor 488, Invitrogen, both at 1:10,000 dilution) for $1 \mathrm{hr}$. Slides were covered with mounting media (Prolong Gold antifade reagent with DAPI, Invitrogen) and images were collected with a confocal laser scanning microscope (LSM 510 META, Carl Zeiss Jena GmbH, Jena, Germany) at $\times 63$ magnification with oil.

\section{Bioinformatics analysis of protein domains}

Sequences for NOTCH2 splicing forms were analyzed for presence of open reading frames http://www.ncbi.nlm. nih.gov/projects/gorf/ and putative conserved domains http://www.ncbi.nlm.nih.gov/Structure/cdd/wrpsb.cgi. Molecular weight of protein isoforms was calculated with Protein Calculator v3.3 http://www.scripps.edu/ cdputnam/protcalc.html.

\section{List of Abbreviations}

GWAS: genome-wide association study; SNP: single nucleotide polymorphism; BC: breast cancer; LD: linkage disequilibrium; ER: estrogen receptor; PR: progesterone receptor; HER-2: human epidermal growth factor receptor 2.

\section{Additional material}

Additional file 1 Table S1. Expression of FL-NOTCH2 in breast tumor samples. Table S2. Expression of FL-NOTCH2 in blood samples from breast cancer patients. Table S3. Expression of FL-NOTCH2 and TR-NOTCH2 in normal breast samples. Table S4. Expression of FL-NOTCH2 in purified peripheral blood monocytes from healthy controls. Table S5. Pearson correlation coefficient between NOTCH2 expression and copy number variation. Table S6. Test for effect of CNVs on association of rs11249433 with NOTCH2 expression. Table S7. Fold difference in expression of FL-NOTCH2 compared to TR-NOTCH2 in NCl-60 cancer cell lines and a panel of normal and tumor human tissues. Table S8. Expression of TR-NOTCH2 in breast tumor and blood samples. Table S9. List of primers and assays. Figure S1. Expression of two splicing forms of NOTCH2 in blood, tumor and normal breast tissue samples.

\section{Competing interests}

The authors declare that they have no competing interests.

\section{Authors' contributions}

YPF, HE and LPO designed the study; HLH, SDF, SA, BN, ALBD and VNK provided samples; YPF, HE, AK, JPA, TMH, IK, PPG, AS performed the study; YPF, HE and LPO wrote the paper. All authors approved the final version of the manuscript and its submission for publication.

\section{Acknowledgements}

The study was supported by intramural research program of $\mathrm{NCI} / \mathrm{NIH}$, the Norwegian Research council grants 155218/N40, 175240/S10 to ALBD, FUGE-NFR 181600/N11 to VNK and a Swizz Bridge Award to ALBD, and the Norwegian Cancer Society grants D99061 to ALBD and D03067 to VNK.

\section{Author Details}

${ }^{1}$ Laboratory of Translational Genomics, Division of Cancer Epidemiology and Genetics, National Cancer Institute, National Institutes of Health, Bethesda, MD, USA, 2Department of Genetics, Institute for Cancer Research, Oslo University Hospital Radiumhospitalet, Montebello, Oslo, Norway, ${ }^{3}$ Faculty Division of Medicine, Radiumhospitalet, The Norwegian Radium Hospital, University of Oslo, Oslo, Norway, ${ }^{4}$ Laboratory of Human Carcinogenesis, Center for Cancer Research, National Cancer Institute, National Institutes of Health, Bethesda, MD, USA, 5 Department of Clinical Cancer Research, Cancer Clinic, Oslo University Hospital Radiumhospitalet, Oslo, Norway, ${ }^{6}$ Department of Oncology, Cancer Clinic, Oslo University Hospital Radiumhospitalet, Oslo, Norway and ${ }^{7}$ Institute for Clinical Epidemiology and Molecular Biology (EpiGen), Faculty of Medicine, University of Oslo, Oslo, Norway

Received: 18 December 2009 Accepted: 19 May 2010

Published: 19 May 2010

\section{References}

1. Ahmed S, Thomas G, Ghoussaini M, Healey CS, Humphreys MK, Platte R, Morrison J, Maranian M, Pooley KA, Luben R, et al:: Newly discovered breast cancer susceptibility loci on 3p24 and 17q23.2. Nat Genet 2009, 41:585-590

2. Gold B, Kirchhoff T, Stefanov S, Lautenberger J, Viale A, Garber J, Friedman E, Narod S, Olshen AB, Gregersen P, et al:: Genome-wide association study provides evidence for a breast cancer risk locus at 6q22.33. Proc Natl Acad Sci USA 2008, 105:4340-4345.

3. Hunter DJ, Kraft P, Jacobs KB, Cox DG, Yeager M, Hankinson SE, Wacholder S, Wang Z, Welch R, Hutchinson A, et al:: A genome-wide association study identifies alleles in FGFR2 associated with risk of sporadic postmenopausal breast cancer. Nat Genet 2007, 39:870-874.

4. Thomas G, Jacobs KB, Kraft P, Yeager M, Wacholder S, Cox DG, Hankinson SE, Hutchinson A, Wang Z, Yu K, et al: A multistage genome-wide association study in breast cancer identifies two new risk alleles at 1p11.2 and 14q24.1 (RAD51L1). Nat Genet 2009, 41:579-584.

5. Easton DF, Pooley KA, Dunning AM, Pharoah PD, Thompson D, Ballinger DG, Struewing JP, Morrison J, Field H, Luben R, et al.: Genome-wide association study identifies novel breast cancer susceptibility loci. Nature 2007, 447:1087-1093.

6. Stacey SN, Manolescu A, Sulem P, Rafnar T, Gudmundsson J, Gudjonsson SA, Masson G, Jakobsdottir M, Thorlacius S, Helgason A, et al:: Common variants on chromosomes $2 \mathrm{q} 35$ and $16 \mathrm{q} 12$ confer susceptibility to estrogen receptor-positive breast cancer. Nat Genet 2007, 39:865-869.

7. Stacey SN, Manolescu A, Sulem P, Thorlacius S, Gudjonsson SA, Jonsson GF, Jakobsdottir M, Bergthorsson JT, Gudmundsson J, Aben KK, et al: Common variants on chromosome $5 \mathrm{p} 12$ confer susceptibility to estrogen receptor-positive breast cancer. Nat Genet 2008, 40:703-706.

8. Lynn A, Ashley T, Hassold T: Variation in human meiotic recombination. Annu Rev Genomics Hum Genet 2004, 5:317-349.

9. The International HapMap Project [http://hapmap.org/

10. Payne SJ, Bowen RL, Jones JL, Wells CA: Predictive markers in breast cancer--the present. Histopathology 2008, 52:82-90.

11. Lacroix M, Toillon RA, Leclercq G: 553 and breast cancer, an update. Endocr Relat Cancer 2006, 13:293-325.

12. Perou CM, Sorlie T, Eisen MB, Rijn M van de, Jeffrey SS, Rees CA, Pollack JR, Ross DT, Johnsen H, Akslen LA, et al: Molecular portraits of human breast tumours. Nature 2000, 406:747-752.

13. Sorlie T, Tibshirani R, Parker J, Hastie T, Marron JS, Nobel A, Deng S, Johnsen H, Pesich R, Geisler S, et al:: Repeated observation of breast tumor subtypes in independent gene expression data sets. Proc Natl Acad Sci USA 2003, 100:8418-8423.

14. Sorlie T, Perou CM, Tibshirani R, Aas T, Geisler S, Johnsen H, Hastie T, Eisen MB, Rijn M van de, Jeffrey SS, et al:: Gene expression patterns of breast carcinomas distinguish tumor subclasses with clinical implications. Proc Natl Acad Sci USA 2001, 98:10869-10874.

15. Langerod A, Zhao H, Borgan O, Nesland JM, Bukholm IR, Ikdahl T, Karesen $R$, Borresen-Dale $A L$, Jeffrey SS: TP53 mutation status and gene expression profiles are powerful prognostic markers of breast cancer. Breast Cancer Res 2007, 9:R30.

16. Jia L, Landan G, Pomerantz M, Jaschek R, Herman P, Reich D, Yan C, Khalid $O$, Kantoff $P$, Oh W, et al:: Functional enhancers at the gene-poor $8 q 24$ cancer-linked locus. PLoS Genet 2009, 5:e1000597. 
17. Meyer KB, Maia AT, O'Reilly M, Teschendorff AE, Chin SF, Caldas C, Ponder BA: Allele-specific up-regulation of FGFR2 increases susceptibility to breast cancer. PLoS Biol 2008, 6:e108.

18. Pomerantz MM, Ahmadiyeh N, Jia L, Herman P, Verzi MP, Doddapaneni $H$, Beckwith CA, Chan JA, Hills A, Davis M, et al: The 8q24 cancer risk variant rs6983267 shows long-range interaction with MYC in colorectal cancer. Nat Genet 2009, 41:882-884.

19. Tuupanen S, Turunen M, Lehtonen R, Hallikas O, Vanharanta S, Kivioja T, Bjorklund M, Wei G, Yan J, Niittymaki I, et al:: The common colorectal cancer predisposition SNP rs6983267 at chromosome 8q24 confers potential to enhanced Wnt signaling. Nat Genet 2009, 41:885-890.

20. Artavanis-Tsakonas S, Rand MD, Lake RJ: Notch signaling: cell fate control and signal integration in development. Science 1999, 284:770-776.

21. Shimizu K, Chiba S, Hosoya N, Kumano K, Saito T, Kurokawa M, Kanda Y, Hamada Y, Hirai H: Binding of Delta1, Jagged1, and Jagged2 to Notch2 rapidly induces cleavage, nuclear translocation, and hyperphosphorylation of Notch2. Mol Cell Biol 2000, 20:6913-6922

22. Mumm JS, Kopan R: Notch signaling: from the outside in. Dev Bio/ 2000, 228:151-165.

23. Wu F, Stutzman A, Mo YY: Notch signaling and its role in breast cancer. Front Biosci 2007, 12:4370-4383.

24. Hirose H, Ishii H, Mimori K, Ohta D, Ohkuma M, Tsujii H, Saito T, Sekimoto M, Doki Y, Mori M: Notch pathway as candidate therapeutic target in Her2/Neu/ErbB2 receptor-negative breast tumors. Oncol Rep 23:35-43.

25. Parr C, Watkins G, Jiang WG: The possible correlation of Notch-1 and Notch-2 with clinical outcome and tumour clinicopathological parameters in human breast cancer. Int J Mol Med 2004, 14:779-786.

26. Li FP, Fraumeni JF Jr: Soft-tissue sarcomas, breast cancer, and other neoplasms. A familial syndrome? Ann Intern Med 1969, 71:747-752.

27. Bossi G, Sacchi A: Restoration of wild-type $p 53$ function in human cancer: relevance for tumor therapy. Head Neck 2007, 29:272-284.

28. Petitjean A, Mathe E, Kato S, Ishioka C, Tavtigian SV, Hainaut P, Olivier M: Impact of mutant p53 functional properties on TP53 mutation patterns and tumor phenotype: lessons from recent developments in the IARC TP53 database. Hum Mutat 2007, 28:622-629.

29. IARC TP53 Database [http://www-p53.iarc.fr/]

30. Ohishi K, Varnum-Finney B, Flowers D, Anasetti C, Myerson D, Bernstein ID: Monocytes express high amounts of Notch and undergo cytokine specific apoptosis following interaction with the Notch ligand, Delta-1. Blood 2000, 95:2847-2854

31. Redon R, Ishikawa S, Fitch KR, Feuk L, Perry GH, Andrews TD, Fiegler H, Shapero MH, Carson AR, Chen W, et al:: Global variation in copy number in the human genome. Nature 2006, 444:444-454.

32. Zeggini E, Scott L, Saxena R, Voight BF, Marchini JL, Hu T, de Bakker PI, Abecasis GR, Almgren P, Andersen G, et al:: Meta-analysis of genomewide association data and large-scale replication identifies additional susceptibility loci for type 2 diabetes. Nat Genet 2008, 40:638-645.

33. Fiuza UM, Arias AM: Cell and molecular biology of Notch. J Endocrinol 2007, 194:459-474.

34. Shankavaram UT, Reinhold WC, Nishizuka S, Major S, Morita D, Chary KK, Reimers MA, Scherf U, Kahn A, Dolginow D, et al:: Transcript and protein expression profiles of the $\mathrm{NCl}-60$ cancer cell panel: an integromic microarray study. Mol Cancer Ther 2007, 6:820-832

35. Prokunina-Olsson L, Kaplan LM, Schadt EE, Collins FS: Alternative splicing of TCF7L2 gene in omental and subcutaneous adipose tissue and risk of type 2 diabetes. PLoS One 2009, 4:e7231.

36. Fortini ME: Notch signaling: the core pathway and its posttranslational regulation. Dev Cell 2009, 16:633-647.

37. Karsan A: Notch and integrin affinity: a sticky situation. Sci Signal 2008, 1:pe2.

38. Shih le M, Wang TL: Notch signaling, gamma-secretase inhibitors, and cancer therapy. Cancer Res 2007, 67:1879-1882.

39. Alimirah F, Panchanathan R, Davis FJ, Chen J, Choubey D: Restoration of p53 expression in human cancer cell lines upregulates the expression of Notch 1: implications for cancer cell fate determination after genotoxic stress. Neoplasia 2007, 9:427-434.

40. Yugawa T, Handa K, Narisawa-Saito M, Ohno S, Fujita M, Kiyono T: Regulation of Notch1 gene expression by p53 in epithelial cells. Mol Cell Biol 2007, 27:3732-3742.

41. Bouras T, Pal B, Vaillant F, Harburg G, Asselin-Labat ML, Oakes SR, Lindeman GJ, Visvader JE: Notch signaling regulates mammary stem cell function and luminal cell-fate commitment. Cell Stem Cell 2008, 3:429-441.

42. Boersma BJ, Howe TM, Goodman JE, Yfantis HG, Lee DH, Chanock SJ, Ambs S: Association of breast cancer outcome with status of $\mathrm{p} 53$ and MDM2 SNP309. J Natl Cancer Inst 2006, 98:911-919.

43. Wiedswang G, Borgen E, Karesen R, Kvalheim G, Nesland JM, Qvist H, Schlichting E, Sauer T, Janbu J, Harbitz T, Naume B: Detection of isolated tumor cells in bone marrow is an independent prognostic factor in breast cancer. J Clin Oncol 2003, 21:3469-3478.

44. Elston EW, Ellis IO: Method for grading breast cancer. J Clin Pathol 1993, 46:189-190

45. Landmark-Hoyvik H, Reinertsen KV, Loge JH, Fossa SD, Borresen-Dale AL, Dumeaux V: Alterations of gene expression in blood cells associated with chronic fatigue in breast cancer survivors. Pharmacogenomics $J$ 2009, 9:333-340.

46. Reinertsen KV, Cvancarova M, Wist E, Bjoro T, Dahl AA, Danielsen T, Fossa SD: Thyroid function in women after multimodal treatment for breast cancer stage II/III: comparison with controls from a population sample. Int J Radiat Oncol Biol Phys 2009, 75:764-770.

47. Prokunina-Olsson L, Welch C, Hansson O, Adhikari N, Scott LJ, Usher N, Tong M, Sprau A, Swift A, Bonnycastle LL, et al:: Tissue-specific alternative splicing of TCF7L2. Hum Mol Genet 2009, 18:3795-3804.

48. Sorlie T, Johnsen H, Vu P, Lind GE, Lothe R, Borresen-Dale AL: Mutation screening of the TP53 gene by temporal temperature gradient gel electrophoresis. Methods Mol Biol 2005, 291:207-216.

49. GK S: Limma: linear models for microarray data. In Bioinformatics and Computational Biology Solutions using R and Bioconductor New York: Springer; 2005:397-420.

50. Kim H, Golub GH, Park H: Missing value estimation for DNA microarray gene expression data: local least squares imputation. Bioinformatics 2005, 21:187-198.

51. McNeill RE, Miller N, Kerin MJ: Evaluation and validation of candidate endogenous control genes for real-time quantitative PCR studies of breast cancer. BMC Mol Biol 2007, 8:107.

52. Reiner A, Yekutieli D, Benjamini Y: Identifying differentially expressed genes using false discovery rate controlling procedures. Bioinformatics 2003, 19:368-375.

53. Mi H, Thomas P: PANTHER Pathway: An Ontology-Based Pathway Database Coupled with Data Analysis Tools. Methods Mol Biol 2009, 563:123-140.

54. Applied Biosystems: User Bulletin \#2, ABI Prism 7700 Sequence Detection System. Relative Quantification of Gene Expression. [http:// www3.appliedbiosystems.com/cms/groups/mcb support/documents/ generaldocuments/cms 040980.pdf].

doi: $10.1186 / 1476-4598-9-113$

Cite this article as: Fu et al, NOTCH2 in breast cancer: association of SNP rs11249433 with gene expression in ER-positive breast tumors without TP53 mutations Molecular Cancer 2010, 9:113

\section{Submit your next manuscript to BioMed Central and take full advantage of:}

- Convenient online submission

- Thorough peer review

- No space constraints or color figure charges

- Immediate publication on acceptance

- Inclusion in PubMed, CAS, Scopus and Google Scholar

- Research which is freely available for redistribution 